OPEN ACCESS

Edited by:

Timothy S. Fisher,

University of California, Los Angeles,

United States

Reviewed by:

Tanvir I. Farouk,

University of South Carolina,

United States

Khanh Duc Cung,

Southwest Research Institute

United States

Jamie Mi,

Peking University, China

${ }^{*}$ Correspondence:

Chiara Galletti

chiara.galletti@unipi.it

Alessandro Parente

Alessandro.Parente@ulb.be

Specialty section: This article was submitted to

Thermal and Mass Transport,

a section of the journal

Frontiers in Mechanical Engineering

Received: 07 June 2019

Accepted: 22 January 2020

Published: 04 March 2020

Citation:

Ferrarotti M, Amaduzzi R, Bascherini D, Galletti $C$ and Parente $A$ (2020) Heat Release Rate Markers for the Adelaide Jet in Hot Coflow Flame.

Front. Mech. Eng. 6:5.

doi: 10.3389/fmech.2020.00005

\section{Heat Release Rate Markers for the Adelaide Jet in Hot Coflow Flame}

\author{
Marco Ferrarotti ${ }^{1,2}$, Ruggero Amaduzzi ${ }^{1}$, Davide Bascherini ${ }^{3}$, Chiara Galletti $i^{3 *}$ and \\ Alessandro Parente ${ }^{1 *}$ \\ ${ }^{1}$ Aero-Thermo-Mechanics Laboratory, Ecole Polytechnique de Bruxelles, Université Libre de Bruxelles, Brussels, Belgium, \\ 2 Service de Thermique et de Combustion, Université de Mons, Mons, Belgium, ${ }^{3}$ Civil and Industrial Engineering Department, \\ University of Pisa, Pisa, Italy
}

In the present work, the correlation between the Heat Releaser Rate (HRR) and species mole fractions and net reaction rates is studied. The PaSR closure model is employed in a RANS framework to implement a detailed kinetic scheme, including the excited species $\mathrm{OH}^{*}$, used as a HRR marker. The effect of oxygen dilution on the combustion regime is investigated, as it can lead to Moderate or Intense Low-Oxygen Dilution (MILD) conditions. Two cases with different levels of oxygen concentration are analyzed. The results suggest the possibility of combining chemical species to construct an appropriate scalar to achieve better correlation with the HRR. It is found that typical markers such as radicals $\mathrm{O}, \mathrm{OH}, \mathrm{OH}^{*}$ correlate fairly well with the HRR but improved correlations can be achieved with appropriate species mole fractions combinations, particularly for the MILD region of the flame.

Keywords: heat release rate, heat release rate markers, $\mathrm{OH}^{*}$, laser induced fluorescence, jet in hot coflow, Moderate or Intense Low-Oxygen Dilution

\section{INTRODUCTION}

The Heat Release Rate (HRR) is a key physical quantity in combustion processes. It represents the amount of heat released per unit of time and space due to chemical reactions. Its spatial distribution directly influences important physical phenomena such as flame-turbulence interactions, sound generation and its interaction with flames. This latter may results in combustion instabilities, thus affecting the behavior of practical devices, such as gas turbines (Nikolaou and Swaminathan, 2014).

The mathematical expression of HRR is:

$$
H R R=\sum_{\alpha=1}^{N} \dot{\omega}_{\alpha} h_{f, \alpha}^{0}
$$

where $N$ is the number of species, $\dot{\omega}_{\alpha}$ is the reaction rate of the $\alpha$-th chemical species, and $h_{f, \alpha}^{0}$ is its standard enthalpy of formation. Clearly, a direct measurement of the HRR would involve the accurate determination of a significant number of scalars simultaneously (Nikolaou and Swaminathan, 2014). Due to such a high complexity, it is more practical to measure a quantity that presents some correlation with this rate over the relevant range of flame and flow parameters (Najm et al., 1998b), to qualitatively estimate the local HRR.

Generally, chemiluminescence of natural excited species, e.g., $\mathrm{OH}^{*}, \mathrm{CH}^{*}$, (where *denotes an electronically excited state) and Laser-Induced Fluorescence (LIF) techniques 
(Najm et al., 1998a,b; Paul and Najm, 1998; Röder et al., 2013; Sidey and Mastorakos, 2015) are used to identify the reaction zone and its topology. However, the choice of the scalars able to identify the reaction region can be influenced by the specific chemical-physical behavior of the combustion process, determined in turn both by operative conditions and fuel mixture (Najm et al., 1998a,b; Nikolaou and Swaminathan, 2014). For instance, Vagelopoulos and Frank (2005) showed that the $\mathrm{CH}$ marker provides a reasonable correlation with the HRR only for undiluted reactant mixtures with equivalence ratios, $\phi$, of $0.8-$ 1.2, whereas Najm et al. (1998a,b) and Paul and Najm (1998) showed that the formyl radical, HCO, is a good HRR-marker for stoichiometric or slightly rich $(\phi=1.2)$ methane and dimethyl ether-air laminar flames. Moreover, the flame stretch effects coming from flame-vortex interaction do not significantly influence this correlation (Najm et al., 1998b). According to the authors, the robust correlation between HRR and HCO concentration may be attributed to three main reasons: (1) HCO is a major intermediate species in oxydation of $\mathrm{CH}_{4}$ to $\mathrm{CO}_{2} ;(2)$ its concentration is directly dependent on its production rate; (3) HCO production is directly dependent on the concentration of $\mathrm{CH}_{2} \mathrm{O}$, that in turn directly depends on the reaction $\mathrm{CH}_{3}+$ $\mathrm{O}<=>\mathrm{CH}_{2} \mathrm{O}+\mathrm{H}$, which shows the largest fractional influence on heat release rate (Paul and Najm, 1998). Nevertheless, Minamoto and Swaminathan (2014), Mulla et al. (2016), and Nikolaou and Swaminathan (2014) highlighted the difficulty of accurately measuring $\mathrm{HCO}$ concentration due to its low signal to noise ratio, thus suggesting to use the more reliable product of $\mathrm{OH}$ and $\mathrm{CH}_{2} \mathrm{O}$ local signals. Indeed, such species are involved as reactants in $\mathrm{HCO}$ formation from formaldehyde through the reaction $\mathrm{OH}+\mathrm{CH}_{2} \mathrm{O}<=>\mathrm{HCO}+\mathrm{H}_{2} \mathrm{O}$. This reconstructed LIF-signal was demonstrated to be a clear HRR-marker for the investigated conditions. Up to now, a wide number of different analysis (Fayoux et al., 2005; Richter et al., 2005; Li et al., 2018) on flame topology has relied on this assumption. Sidey and Mastorakos (2015) compared the presence of $\mathrm{OH}$ and $\mathrm{OH}^{*}$ with the flame primary heat release region under MILD conditions, suggesting that the sole $\mathrm{OH}$ may not be a comprehensive HRR marker for MILD regime.

In more recent studies, Nikolaou and Swaminathan (2014) and Mulla et al. (2016) re-examined the validity of this reaction rate as flame marker for a certain number of combustion conditions. In particular, using Direct Numerical Simulations (DNS) data, they investigated undiluted and diluted methane-air flames, and multicomponent fuel mixtures under both laminar and turbulent conditions. The diluted case operated in Moderate or Intense Low oxygen Dilution (MILD) conditions (Minamoto and Swaminathan, 2014). Remarkable findings shown were: (1) a large fractional contribution of a reaction to the HRR does not automatically imply that this will have a good correlation with the HRR (Nikolaou and Swaminathan, 2014); thus, the rate of the aforementioned reaction, $\mathrm{CH}_{3}+\mathrm{O}<=>\mathrm{CH}_{2} \mathrm{O}+\mathrm{H}$, which often shows a high fractional influence on HRR, is not necessarily well correlated with the HRR. (2) HRR correlation is strongly dependent on the equivalence ratio. As a consequence, alternative markers were proposed. The product of $\mathrm{H}$ and $\mathrm{CH}_{2} \mathrm{O}$ concentrations, corresponding to reaction $\mathrm{H}+\mathrm{CH}_{2} \mathrm{O}<=>$
$\mathrm{HCO}+\mathrm{H}_{2}$, instead of $\mathrm{OH}$ and $\mathrm{CH}_{2} \mathrm{O}$ ones was suggested for turbulent MILD and conventional premixed methane-air flames. The viability of $\mathrm{H}-\mathrm{CH}_{2} \mathrm{O}$ product LIF signal was demonstrated in Mulla et al. (2016).

The aim of this study is to add further understanding on the adequacy of the various HRR markers under diluted condition of a methane/hydrogen-air mixture for both MILD and notMILD conditions. To this purpose, the widely studied Adelaide Jet in Hot Coflow (JHC) burner (Dally et al., 2002; Medwell et al., 2007; Wang et al., 2011) is modeled following Christo and Dally (2005), Aminian et al. (2012), Parente et al. (2016), Ferrarotti et al. (2019). Firstly, spatial correlations of chemical species and reaction rates with the local HRR are studied. Thence, appropriate combinations of species mole fractions are also taken into consideration and compared with conventional markers.

\section{METHODOLOGY}

\subsection{Adelaide Jet in Hot Coflow Burner}

The Adelaide JHC (Dally et al., 2002) has been extensively studied and modeled in literature because of its ability to emulate the MILD combustion regime as well as the large number of available experimental data. Hence, it represents a reference test case to validate computational models. For sake of clarity, a sketch of the burner is shown in Figure 1, together with numerical predictions of the $\mathrm{OH}$ radical for the two configurations investigated in this work. Inlet conditions are reported in Table 1. A central fuel jet made up of $\mathrm{CH}_{4}$ and $\mathrm{H}_{2}$ (50/50 by vol.) issues in a hot coflow (temperature of $1300 \mathrm{~K}$ ), made up of combustion products of fixed $\mathrm{CO}_{2}$ and $\mathrm{H}_{2} \mathrm{O}$ (mass fractions $\mathrm{Y}_{\mathrm{CO}_{2}}=6.5 \%$, $\mathrm{Y}_{\mathrm{H}_{2} \mathrm{O}}=5.5 \%$ ) and variable $\mathrm{O}_{2}$ and $\mathrm{N}_{2}$, coming from a secondary burner mounted upstream. The JHC burner is placed in a wind tunnel which feeds room temperature air at the same velocity of the coflow. In the configurations of interest for this study, namely HM1 and HM3 of Dally et al. (2002), coflow oxygen concentrations of $3 \%$ and $9 \%$ by mass, respectively, are considered. The same terminology of Dally et al. (2002) will be used in this paper for these two flames. The strong dilution kept in the HM1 configuration allows to emulate MILD combustion conditions in the first $100 \mathrm{~mm}$ of the flame (Medwell et al., 2007). After that, the entrained air from the surroundings changes the flame structure, which becomes closer to a standard diffusion flame, as shown in Figure 1B.

\subsection{Numerical Model}

Unsteady Favre-Averaged Numerical Simulations (uFANS) were performed using ANSYS Fluent R19.5. A two-dimensional axisymmetric grid, $0.6 \mathrm{~m}$ along axial direction and $0.2 \mathrm{~m}$ wide, of about 35k quadrilateral cells was employed. Two additional meshes were considered to evaluate the Grid Convergence Index (GCI), which was lower than 3\% for temperature and major species. Moreover, a large refinement was set across the reaction zone to well capture gradients of composition and temperature. The standard $\mathrm{k}-\epsilon$ with the first constant of the dissipation rate equation $C_{\epsilon 1}=1.6$ (hence modified for round jets as suggested by Pope, 1978; Christo and Dally, 2005) was chosen as turbulence model. Turbulence-chemistry interactions were modeled using 


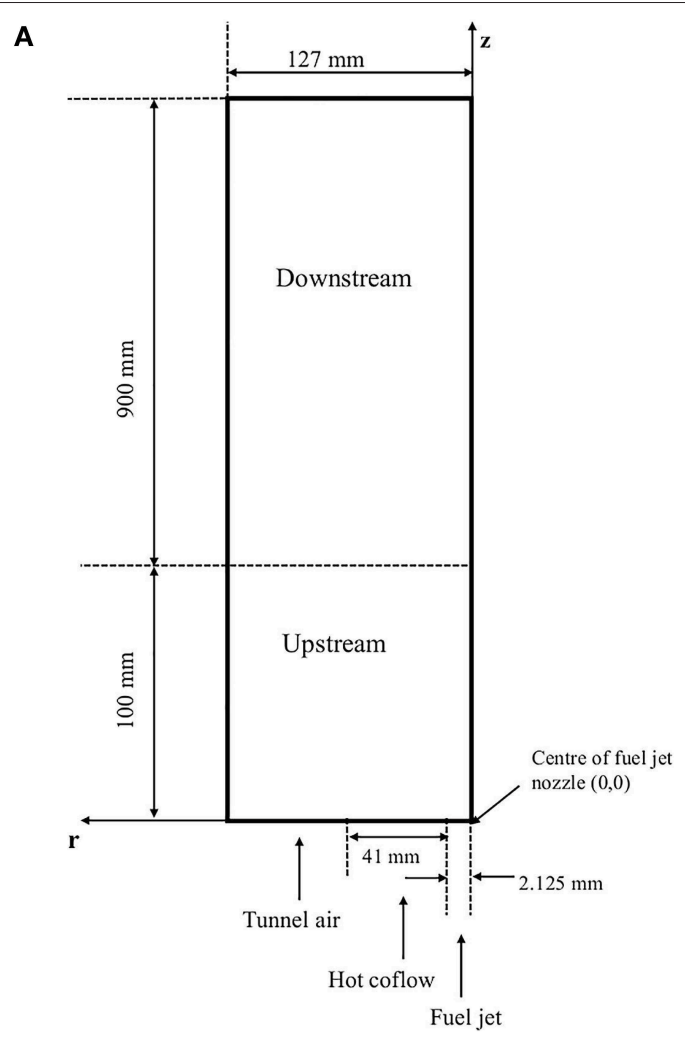

B

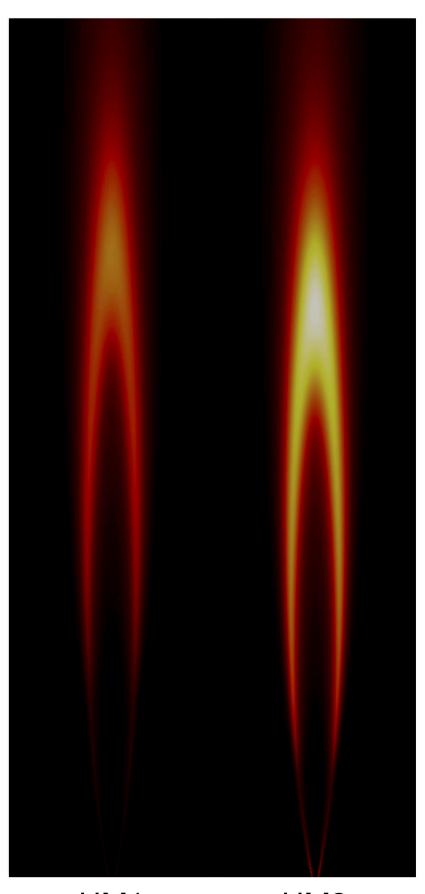

HM1

HM3

FIGURE 1 | (A) 2D sketch of the Adelaide Jet in Hot Coflow (adapted from Li et al., 2018); (B) Numerical predictions of OH for HM1 and HM3 flames.

TABLE 1 | JHC inlet velocities and temperatures.

\begin{tabular}{lccc}
\hline Profiles & Fuel jet & Coflow & Tunnel \\
\hline Velocity $[\mathrm{m} / \mathrm{s}]$ & 58.74 & 3.2 & 3.2 \\
Temperature $[\mathrm{K}]$ & 305 & 1300 & 294 \\
\hline
\end{tabular}

the Partially Stirred Reactor (PaSR) model (Chomiak, 1990; Golovitchev and Chomiak, 2001). As with other reactor based models, the computational cell is split into two zones, one reactive and one in which only mixing occurs. The reactive zone mass fraction is estimated considering both the characteristic chemical and mixing time-scales $\tau_{c}$ and $\tau_{\text {mix }}$ :

$$
\kappa=\frac{\tau_{c}}{\tau_{c}+\tau_{\text {mix }}} .
$$

The approach suggested by Ferrarotti et al. (2019) was used to express $\tau_{\text {mix }}$ : the mixing time-scale is proportional to the integral time-scale $\frac{\kappa}{\epsilon}$ :

$$
\tau_{\text {mix }}=C_{\text {mix }} \frac{\kappa}{\epsilon} .
$$

Based on previous studies (Ferrarotti et al., 2019), a constant $C_{\text {mix }}$ of 0.5 was considered. A dynamic approach (Sanders and Gökalp, 1998; Raman and Pitsch, 2007; Ye, 2011; Li et al., 2018;
Ferrarotti et al., 2019) was then followed: the mixing time-scale $\tau_{\text {mix }}$ is defined based on local properties of the flow field, as it is estimated as the ratio of the mixture fraction variance $Z^{\prime \prime 2}$ to the mixture fraction dissipation rate $\chi$ :

$$
\tau_{\text {mix }}=\frac{\tilde{Z^{\prime \prime 2}}}{\tilde{\chi}} .
$$

Transport equations for the Favre average of the two variables can be written as:

$$
\begin{aligned}
\frac{D \bar{\rho} \widetilde{Z^{\prime \prime 2}}}{D t}= & \frac{\partial}{\partial x_{j}}\left(\rho\left(D_{m}+D_{t}\right) \frac{\partial \widetilde{Z^{\prime \prime 2}}}{\partial x_{j}}\right)+2 \rho D_{t}\left(\frac{\partial \widetilde{Z}}{\partial x_{j}}\right)^{2}-\rho \tilde{\chi} \\
\frac{D \rho \tilde{\chi}}{D t}= & \frac{\partial}{\partial x_{j}}\left(\rho\left(D_{m}+D_{t}\right) \frac{\partial \tilde{\chi}}{\partial x_{j}}\right)-C_{D_{1}} \bar{\rho} \frac{\widetilde{\chi}^{2}}{\widetilde{Z^{\prime \prime 2}}}-C_{D_{2}} \bar{\rho} \frac{\tilde{\chi} \tilde{\epsilon}}{\tilde{\kappa}} \\
& +C_{P_{1}} \frac{\tilde{\chi}}{\widetilde{Z^{\prime 2}}} P_{f}+C_{P_{2}} \frac{\tilde{\chi}}{\tilde{\kappa}} P_{k} .
\end{aligned}
$$

where $Z$ is the mixture fraction, $D_{t}$ is the turbulent diffusivity, $P_{f}=-2 \bar{\rho} \widetilde{u_{k}^{\prime \prime} Z^{\prime \prime}}\left(\frac{\partial \tilde{Z}}{\partial x_{k}}\right)$ is the production of scalar fluctuation and $P_{k}=-\bar{\rho} u_{k}^{\prime \prime} u_{i}^{\prime \prime}\left(\frac{\partial \tilde{U}_{i}}{\partial x_{k}}\right)$ is the production of turbulent kinetic energy. The set of coefficients $C_{P_{1}}, C_{P_{2}}, C_{D_{1}}, C_{D_{2}}$ used is the one proposed by Ye (2011). The discrete ordinate (DO) method was used to solve the radiative transfer equation, estimating 

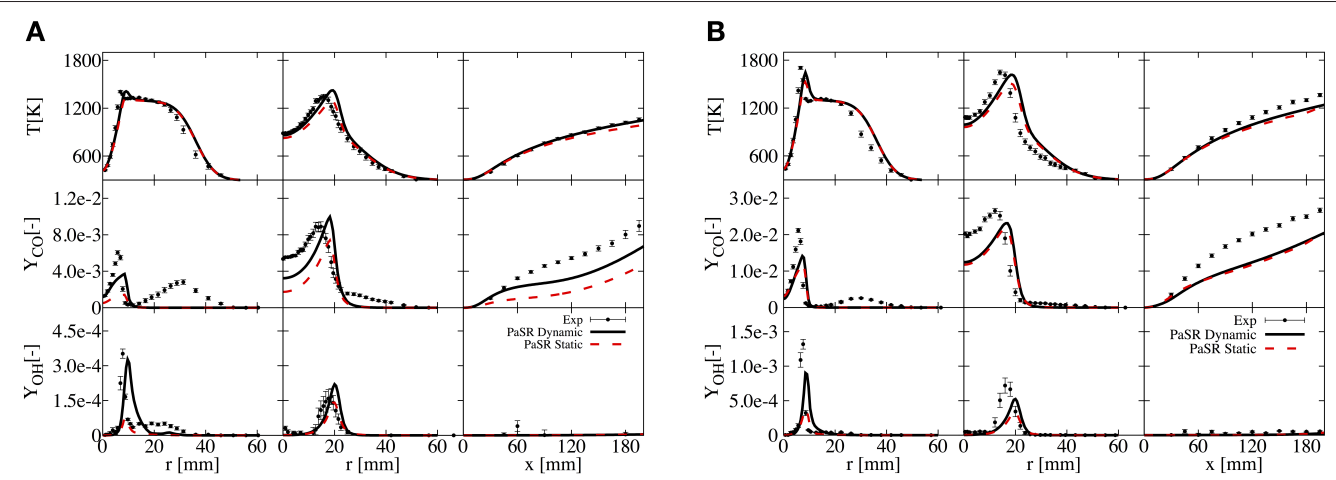

FIGURE 2 | Comparison of $T, \mathrm{OH}$, and $\mathrm{CO}$ for static and dynamic PaSR with experimental data at axial locations of 30 and $120 \mathrm{~mm}$ and along the axis for HM1 (A) and $\mathrm{HM} 3$ (B) configurations.

spectral properties of the gaseous medium with the Weighted Sum of Gray Gases Model (WSGGM). Detailed chemistry was taken into account using the GRI2.11 mechanism (Bowman et al., 2020), excluding nitrogen-containing species. A sub-mechanism assembled by Kathrotia et al. (2012) and used also by Doan et al. (2018) was added to the main mechanism, to account for the conventional HRR-marker $\mathrm{OH}\left(\mathrm{A}^{2} \Sigma^{+}\right)$, namely $\mathrm{OH}^{*} . \mathrm{OH}^{*}$ is generally accepted as a marker for the flame-front structure and heat release rate, therefore its inclusion in the mechanism should enhance the description of the phenomena. This sub-mechanism consists of twelve reactions, whose Arrhenius terms are taken from Kathrotia et al. (2010), Tamura et al. (1998), and Smith et al. (2002). The resulting mechanism contains 32 chemical species and 187 reactions. To reduce the computational time associated to detailed chemistry, the In situ Adaptive Tabulation (ISAT) method by Pope (1997) was adopted with an ISAT tolerance of $10^{-5}$.

\subsection{Analysis}

HRR, chemical species mole fraction $\left(X_{\alpha}\right.$, where $\alpha$ is the species index) and net reaction rate $\left(\dot{\omega}_{r}\right.$, where $r$ is the reaction index) values were sampled along the radial direction at various axial distances from the burner nozzle. Each sampled profile is $50 \mathrm{~mm}$ long starting from the burner axis. Obtained data were used to estimate the metric $Z(v)$ at each axial location as proposed by Nikolaou and Swaminathan (2014), to appreciate how much a scalar $v$ is representative of the HRR. In particular, $Z(v)$ for the radial segment $s$ is defined as:

$$
Z_{s}(\nu)=\sum_{n=1}^{N p}\left(\frac{\left|H R R_{n, s}\right|}{\max _{s}(|H R R|)}-\frac{\left|v_{n, s}\right|}{\max _{s}(|\nu|)}\right)^{2} .
$$

In the equation above, $N p$ indicates the number of points of the radial segment, $\max _{s}(|H R R|)$ and $\max _{s}(v)$ are the maximum HRR and $v$ of that segment, respectively, while $v$ can be any scalar of interest. For the current case, it is either the mole fraction of the $\alpha$ chemical species $X_{\alpha}$, or the reaction rate $\dot{\omega}_{r}$. $Z_{s}(v)$ was normalized as $Z_{s}^{+}=100 \cdot Z_{s} / \max \left(Z_{s}\right)$, as explained by Nikolaou and Swaminathan (2014). The Z-metric gives an idea on how well a normalized scalar reproduces the spatially matched normalized HRR. At each radius, the lowest values of $Z_{s}^{+}(v)$ identifies the scalars that best correlate with the HRR. It is worth to repeat that the fractional contribution of a reaction to the HRR is not a good way to identify the best HRR markers, whereas the $Z$-metric is a more rigorous technique, and for this reason was chosen as benchmark for comparison. If the chosen scalar is the net reaction rate, it may have positive and negative contributions to $Z$, thus giving ambiguous results. However, the top-correlating reactions have either only positive or negative contributions, without influencing the adequacy of the above definition. The results obtained in terms of mole fractions and reactions are presented in Sections 3.1 and 3.2. In Section 3.3, the analysis is also performed substituting to $v$ appropriate combinations of mole fractions to verify if there are products of species concentrations that may be more suitable for HRR identification.

\section{RESULTS AND DISCUSSION}

\subsection{HM1 Case}

The simulation results are first confronted with the experimental data from Dally et al. (2002), considering both static and dynamic approaches. Profiles of temperature, $\mathrm{OH}$ and $\mathrm{CO}$ at the axial locations of 30 and $120 \mathrm{~mm}$, and along the axis are shown in Figure 2 for HM1 (A) and HM3 (B). It can be appreciated how the simulation well reproduce the experimental measurements, as reported in Ferrarotti et al. (2019). Only results from the dynamic approach are presented from here onwards.

Figure 3 show $Z_{s}^{+}\left(X_{\alpha}\right)$ values for the $\mathrm{HM} 1$ case (coflow $Y_{\mathrm{O}_{2}}=$ $3 \%$ ), calculated according to Equation (7) when $v=X_{\alpha}$, namely for all the 32 species of the employed mechanism. Furthermore, the product mole fractions of $\mathrm{OH}$ and $\mathrm{CH}_{2} \mathrm{O}$ proposed by Paul and Najm (1998), and of $\mathrm{H}$ and $\mathrm{CH}_{2} \mathrm{O}$ suggested by Nikolaou and Swaminathan (2014) are also taken into consideration. Six graphics, one for the respective axial location, $x$, collect only the first twelve values of $Z_{s}^{+}\left(X_{\alpha}\right)$ in ascending order. According to Equation (7), the lowest values are representative of best correlations with HRR. At this point, it is worth to remember that MILD combustion is achieved in the first $100 \mathrm{~mm}$ downstream of the burner exit for the HM1 case. After that, the entrained 

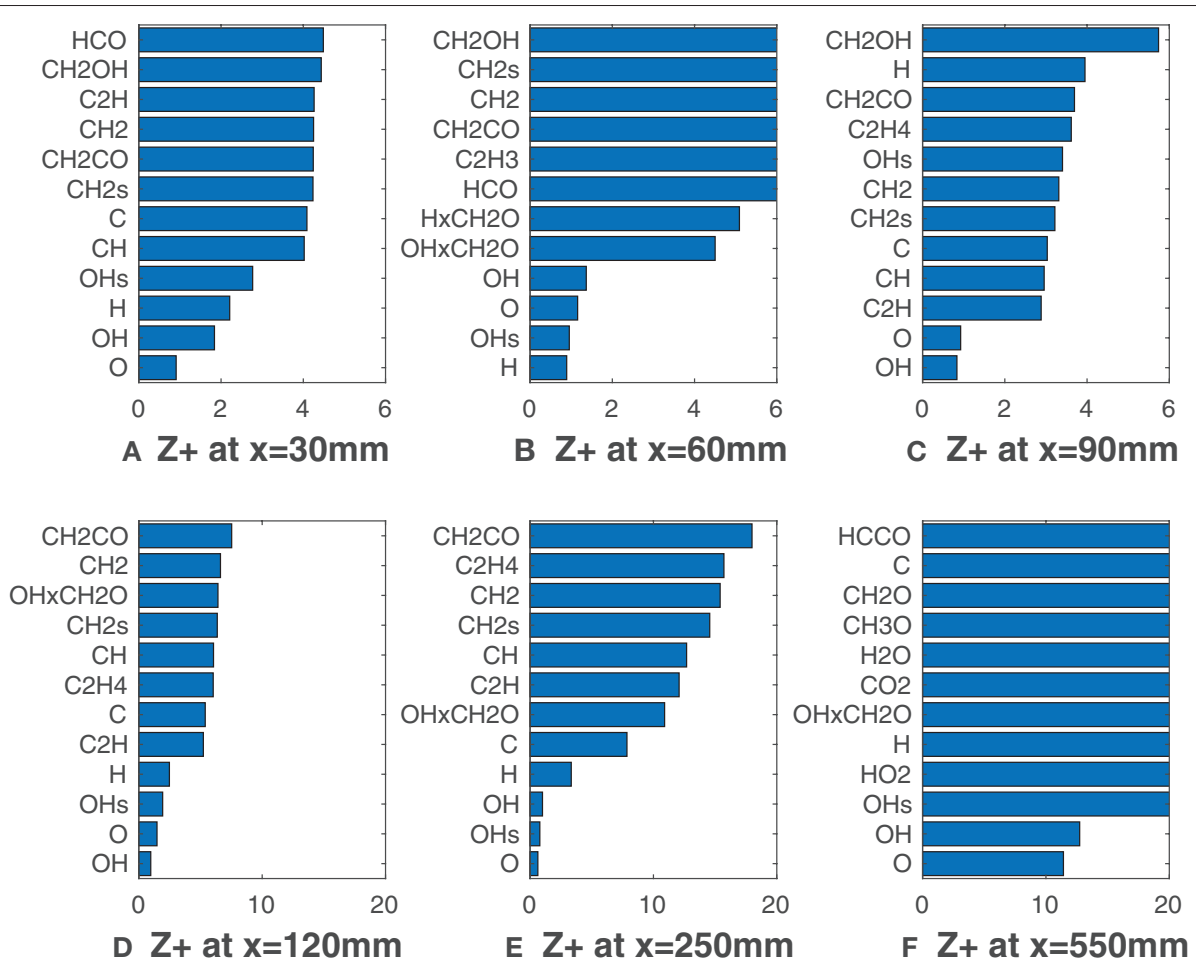

FIGURE 3 | HM1 case: best correlated species at various axial locations. Lower $Z_{s}^{+}\left(X_{\alpha}\right)$ values mean better correlation.

oxygen from the surrounding changes the combustion behavior. As shown in Figure 3A, for $x=30 \mathrm{~mm}$ all the species exhibit rather low values of $Z_{s}^{+}\left(X_{\alpha}\right)$, as $Z^{+}$never exceeds $5 . \mathrm{O}, \mathrm{H}$, and the conventional HRR-markers $\mathrm{OH}$ and $\mathrm{OH}^{*}$ provide the lowest values. At this axial location the flame brush is quite thin and the low $Z_{s}^{+}\left(X_{\alpha}\right)$ for most of the scalars can be attributed to this reason. Figures 3B,C show a different species ranking for $x=60$ $\mathrm{mm}$ and $x=90 \mathrm{~mm}$ : for the former $\mathrm{H}$ and $\mathrm{OH}^{*}$ provide lower values of $Z^{+}$, while $\mathrm{O}$ and $\mathrm{OH}$ are better correlated in the latter. However, at these locations, a clear selection of the best potential HRR markers cannot be made. Besides, $Z_{s}^{+}\left(X_{\alpha}\right)$ is generally low (under 10) for all the listed species suggesting that different scalars could be used to detect the reaction zone. Nevertheless, this behavior changes moving further from the jet nozzle: at $x=120 \mathrm{~mm}$ (Figure 3D) the gap between the four radicals, $\mathrm{O}$, $\mathrm{OH}, \mathrm{OH}^{*}, \mathrm{H}$ and the others becomes higher while the values of $Z_{s}^{+}\left(X_{\alpha}\right)$ grow. This difference is clear in Figure 3E where $\mathrm{O}, \mathrm{OH}$, $\mathrm{OH}^{*}$ are unambiguously the top-three markers, while $\mathrm{H}$ usually presents a slightly lower matching with the HRR. At $x=550$ mm (Figure 3F) and higher distances (not reported here) HRR decreases and all the correlations are lost rapidly. It is interesting to note that the formyl radical, HCO, conventionally used as marker with LIF techniques, displays higher values among the correlated species Moreover, contrary to what proposed by Najm et al. (1998b), the product of $\mathrm{OH}$ and $\mathrm{CH}_{2} \mathrm{O}$ mole fractions does not seem to be a good HRR marker, since its $Z_{s}^{+}$is not within the top-five species. This finding may be due to the different chemical pathway followed when methane is diluted with hydrogen and is consistent with results from Kathrotia et al. (2012).

Figure 4 adds further insights in this behavior, showing the normalized $Z$-metric obtained in terms of reactions rates instead of species concentrations. Hence, in Equation (7) the scalar $v$ is substituted with the kinetic reaction rate, $\dot{\omega}_{r}$ (where the subscript $r$ indicates the reaction). What stands out is that several reactions from the added $\mathrm{OH}\left(A^{2} \Sigma^{+}\right)$sub-mechanism appear among the top correlated reactions at many axial locations, while the reactions $\mathrm{O}+\mathrm{CH}_{3}<=>\mathrm{H}+\mathrm{CH}_{2} \mathrm{O}, \mathrm{OH}+\mathrm{CH}_{2} \mathrm{O}<=>$ $\mathrm{HCO}+\mathrm{H}_{2} \mathrm{O}$ suggested by Najm et al. (1998b) and Paul and Najm (1998) and the reaction $\mathrm{H}+\mathrm{CH}_{2} \mathrm{O}<=>\mathrm{HCO}+\mathrm{H}_{2}$ proposed by Nikolaou and Swaminathan (2014) are not present among the ones reported. This may be due to the fuel enrichment with hydrogen, since the cited literature refers to methane-only configurations. This is in line with the previous observations on mole fractions, which do not identify formaldehyde and formyl radical among the markers. Third-body reactions are present in the top ranking positions throughout the flame. The excitation reaction $\mathrm{H}+\mathrm{O}+\mathrm{M}<=>M+\mathrm{OH}^{*}$ (Kathrotia et al., 2012), together with $\mathrm{CH}+\mathrm{O}_{2}<=>\mathrm{OH}^{*}+\mathrm{CO}$, is responsible for the formation of the common HRR marker (Sidey and Mastorakos, 2015; Doan et al., 2018). At $x=60 \mathrm{~mm}$ and $x=90 \mathrm{~mm}$ (Figures 4B,C) the third-body reaction of oxygen, $2 \mathrm{O}+\mathrm{M}<=>$ $\mathrm{O}_{2}+M$, shows the lowest values of $Z_{s}^{(+)}\left(\omega_{r}\right)$ and remains in the top-seven markers till the last sample. A conspicuous number of reactions involving the hydrogen peroxide, $\mathrm{H}_{2} \mathrm{O}_{2}$, and the hydroperoxyl radical, $\mathrm{HO}_{2}$, replace the previous ones in the last 

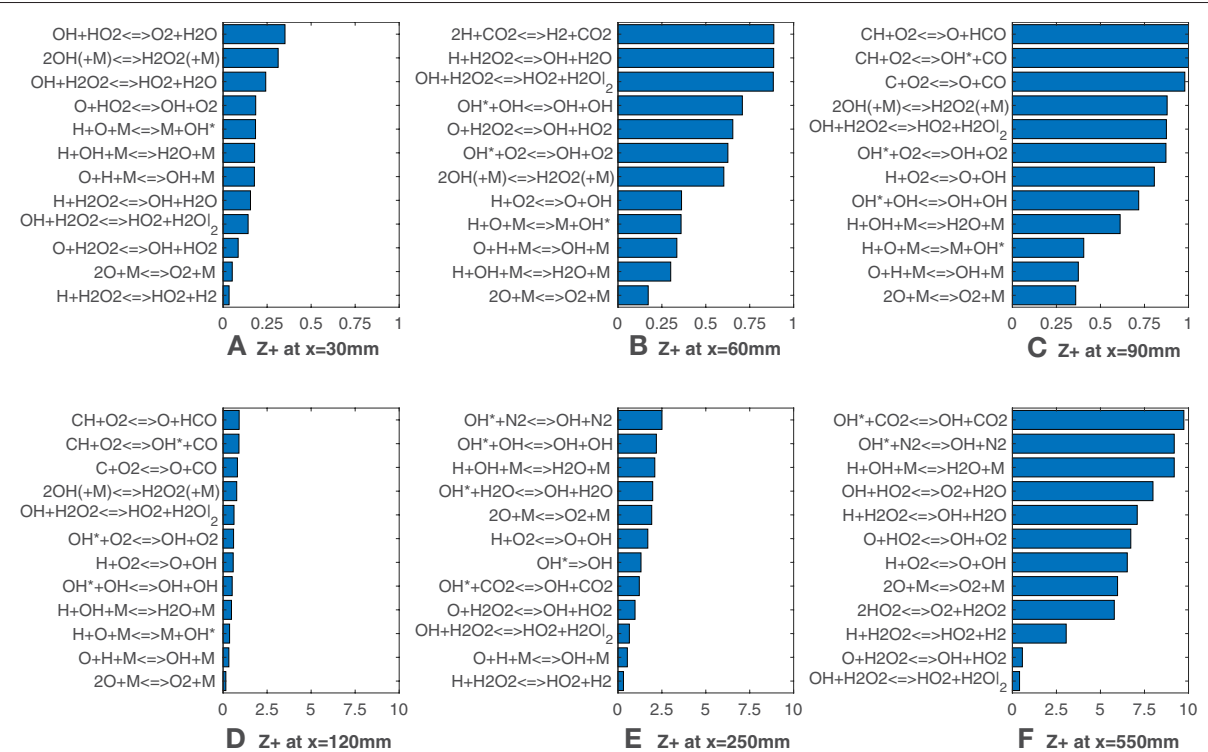

FIGURE 4 | HM1 case: best correlated net reaction rates at various axial locations. Lower $Z_{s}^{+}\left(\dot{\omega}_{r}\right)$ values mean better correlation.

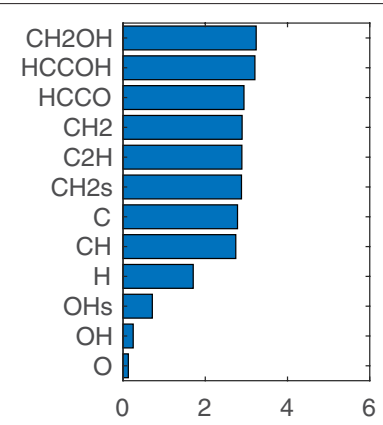

A $Z+$ at $x=30 \mathrm{~mm}$

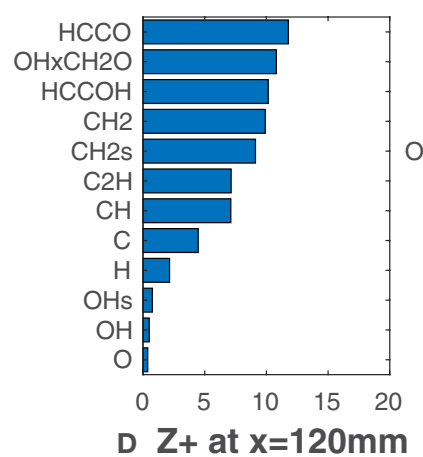

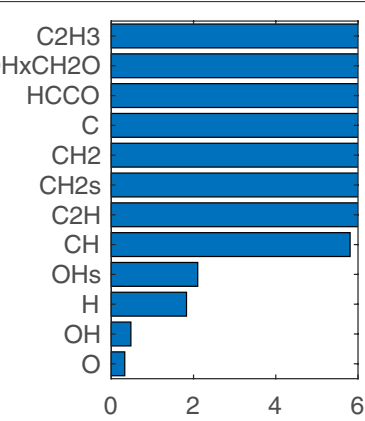

B $Z+$ at $x=60 \mathrm{~mm}$

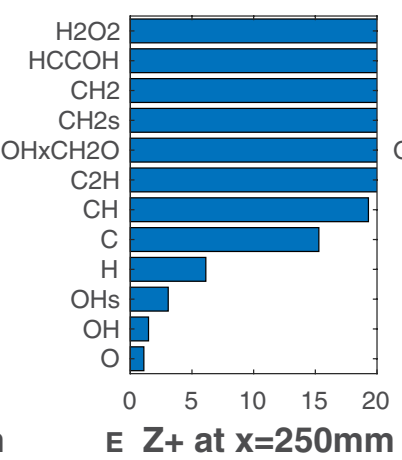

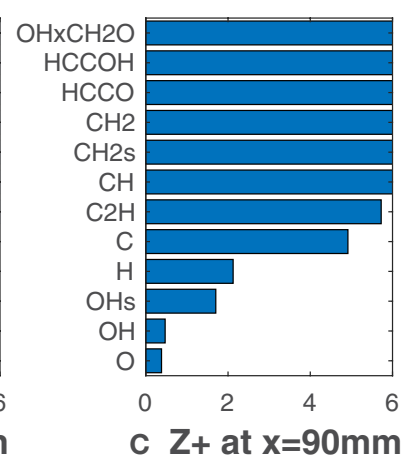

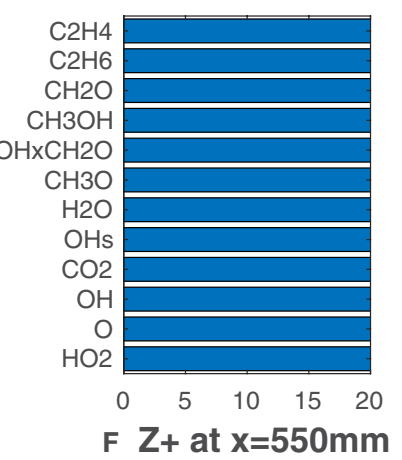

FIGURE 5 | HM3 case: best correlated species at various axial locations. Lower $Z_{s}^{+}\left(X_{\alpha}\right)$ values mean better correlation.

sampled segment at $x=550 \mathrm{~mm}$ (Figure 4F). Moreover, at this axial location, the reactions $\mathrm{H}+\mathrm{HO}_{2}<=>2 \mathrm{OH}$ and $\mathrm{H}+$ $\mathrm{HO}_{2}<=>\mathrm{O}+\mathrm{H}_{2} \mathrm{O}$ do not appear, even though their reaction rates were found to be good HRR indicators by Nikolaou and Swaminathan (2014) for lean to near-stoichiometric methane-air mixtures and especially at low value of HRR.

\subsection{Comparison With HM3 Case}

Figure 5 reports $Z_{s}^{+}\left(X_{\alpha}\right)$ relative to the coflow oxygen concentration of $9 \%$, i.e., HM3 flame. With this configuration the flame is visible since its beginning (Figure 1B), and MILD conditions are not reached. Unlike Figures 3A-D, $\mathrm{O}, \mathrm{OH}$, $\mathrm{OH}^{*}$ radicals show unambiguously greater correlation with 

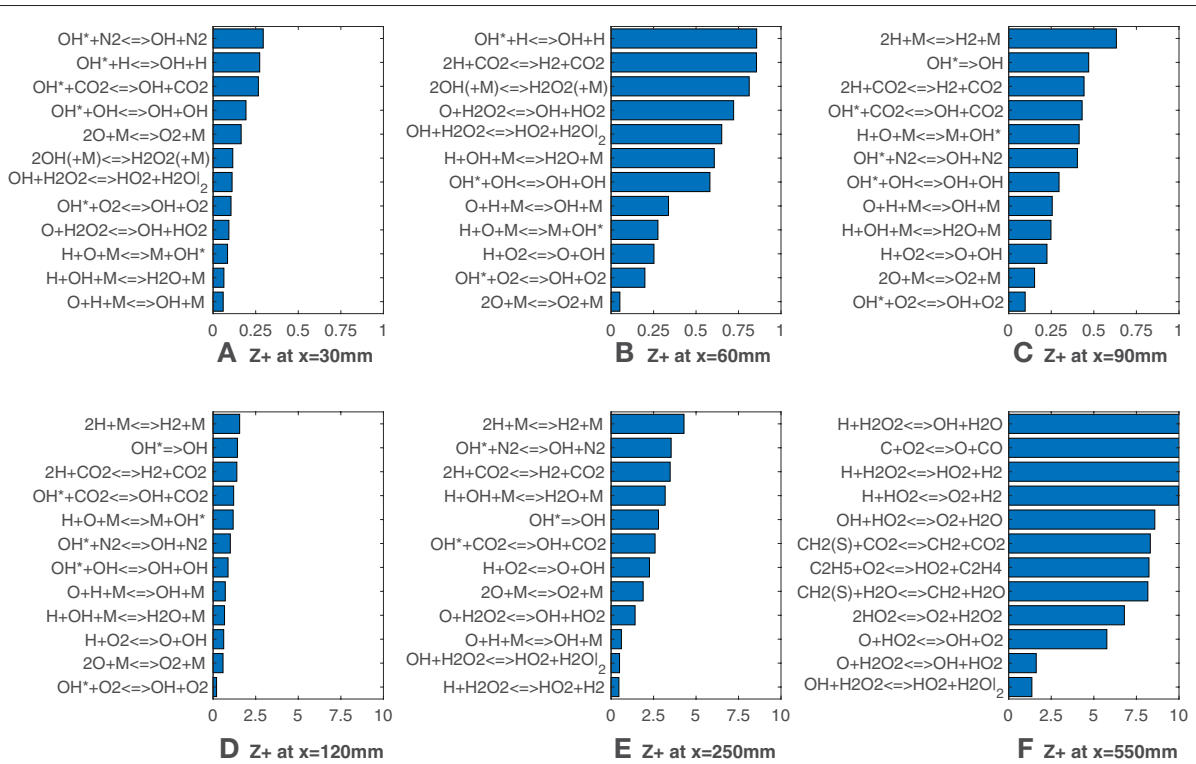

FIGURE 6 | HM3 case: best correlated net reaction rates at various axial locations. Lower $Z_{s}^{+}\left(\dot{\omega}_{r}\right)$ values mean better correlation.

HRR if compared to the other species. $\mathrm{O}$ and $\mathrm{OH}$ present slightly higher $Z_{s}^{+}\left(X_{\alpha}\right)$-values throughout the entire domain. As previously underlined, at long distances HRR decades and $Z_{s}^{+}\left(X_{\alpha}\right)$ increases fast for all the species. It is interesting to note that this last phenomena emerges a bit before if compared to the HM1 case. Indeed, in the HM1 configuration combustion is somewhat slowed down due to MILD conditions. This leads to a slightly longer flame for $Y_{\mathrm{O}_{2}}=3 \%$, explaining why the correlations drop down later with respect to the HM3 case. The product of $\mathrm{OH}$ and $\mathrm{CH}_{2} \mathrm{O}$ mole fractions appears as well in Figure 5, always having a higher $Z_{s}^{+}\left(X_{\alpha}\right)$ value. It is clear that the influence of oxygen concentration plays a significant role in determining the best HRR-markers. For the HM3 case the distinction between the top three markers O, $\mathrm{OH}, \mathrm{OH}^{*}$ and the others is noticeable from the beginning of the combustion process, whereas, for the $3 \%$ coflow case, this distinction becomes clearer only downstream of $100 \mathrm{~mm}$ of flame, due to the higher level of entrained oxygen from surroundings.

Looking now at Figure 6, it is interesting to note that values of $Z_{s}^{+}\left(\dot{\omega}_{r}\right)$ are generally lower up to $90 \mathrm{~mm}$ if compared with the $\mathrm{HM} 1$ case. The $\mathrm{OH}^{*}$ formation reaction appears again as a good indicator of heat release as several reactions from the submechanism are listed. Also in this case, for $x=250 \mathrm{~mm}$ and $x=550 \mathrm{~mm}$ (Figures 6E,F), reactions involving hydroperoxyl radical show a very good agreement with the HRR. In the latter, $\mathrm{OH}+\mathrm{H}_{2} \mathrm{O} 2<=>\mathrm{HO} 2+\mathrm{H} 2 \mathrm{O}$ and $\mathrm{O}+\mathrm{H} 2 \mathrm{O} 2<=>\mathrm{OH}+\mathrm{HO} 2$ cover the first positions, suggesting that their rates could be good HRR markers at this location with the $9 \%$ coflow oxygen concentration.

\subsection{Combinations of Mole Fractions}

Figures 7,8 report $Z_{s}^{+}(v)$ calculated substituting species mole fractions $X_{\alpha}$ and their combinations to $v$. It is noteworthy that several combinations present values lower than the lowest ones recorded in Figures 3, 5. The product of $\mathrm{O}$ and $\mathrm{OH}$ shows a very good agreement with the HRR and is the solution of choice till $x=120 \mathrm{~mm}$ (Figure 7). This notable results may suggest that for MILD combustion under the conditions of interest, an appropriate combination of species can identify the reaction zone more precisely than a single species, thus with less uncertainty on the choice of the right scalar. Just above the combination $\mathrm{OxOH}$ (here $\mathrm{x}$ is the product symbol), combinations of $\mathrm{H}, \mathrm{O}, \mathrm{OH}$ and $\mathrm{OH}^{*}$ show also a very good correlation metric. At higher distances, combinations of these 3 radicals with the major species $\mathrm{H}_{2} \mathrm{O}$ and $\mathrm{CO}_{2}$ are ranked first. As expected, this change occurs first for the HM3 configuration (Figure 8).

The distributions of HRR, mole fraction and combinations are reported and compared in Figure 9. The 6 graphics correspond to 3 positions of the 2 cases studied, i.e., $x=60 \mathrm{~mm}, x=120 \mathrm{~mm}$ and $x=550 \mathrm{~mm}$, respectively. Only radial profiles of the toptwo species and the top-two combinations are drawn together with the HRR. All these scalars are normalized with respect to their own maximum. It is worth noting that both species mole fractions and combinations capture the HRR peak very well in Figures 9A,B,D,E. The main difference is associated to the tails of the curves, for low values of HRR. In particular, using the mole fraction products allows to have a higher correlation in these branches and capture the near-zero HRR behavior. This might also suggest a good detection of local extinction. Different considerations should be done for Figures 9C,F. At $x=550$ $\mathrm{mm}$, the HRR curve is wider and, as stated previously, the sole species are not a very good HRR marker, especially for the HM3 case.

Looking to the contour plots (Figure 10) reported as a qualitative example, it is possible to identify the 3 zones previously underlined. Two black dotted lines divide this zones 


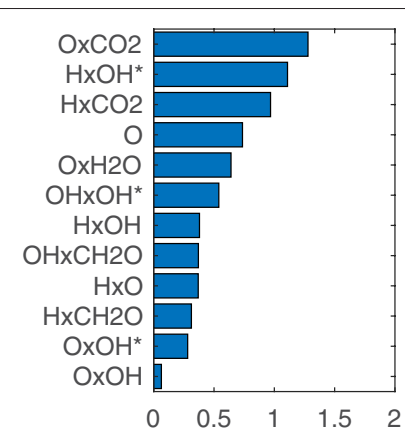

A $Z+$ at $x=30 \mathrm{~mm}$

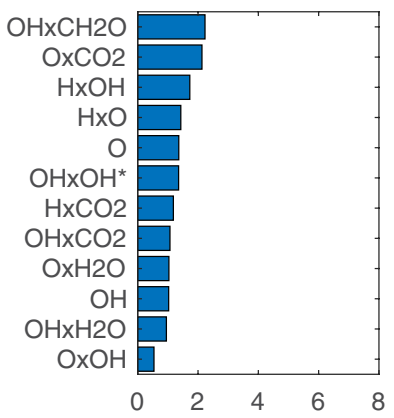

D Z+ at $x=120 \mathrm{~mm}$

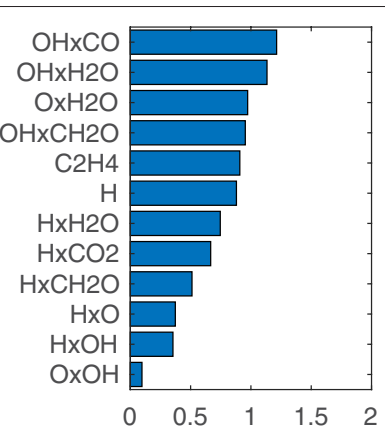

B Z+ at $x=60 \mathrm{~mm}$

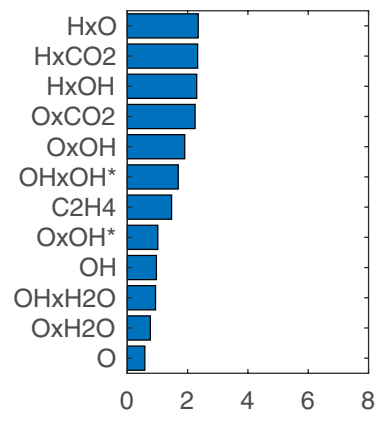

E Z+ at $x=250 \mathrm{~mm}$
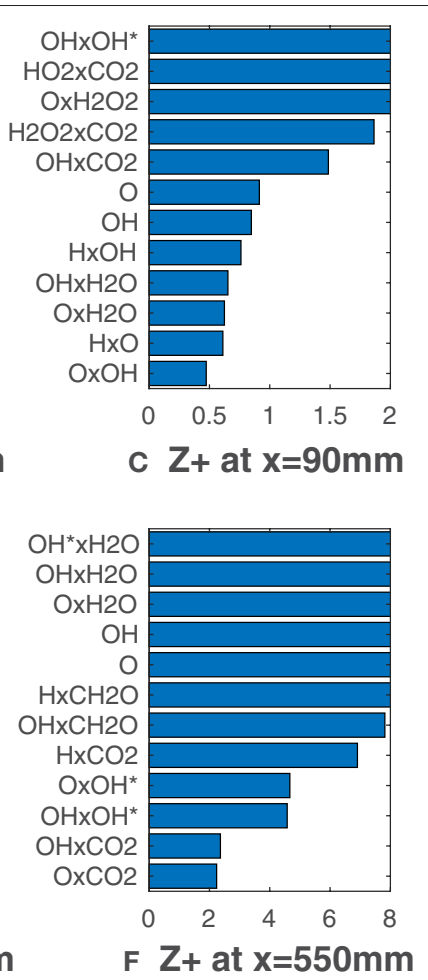

FIGURE 7 | HM1 case: best correlated markers at various axial locations. Lower $Z_{s}^{+}(v)$ values mean better correlation. Here $v$ comprehends both $X_{\alpha}$ and their combinations.

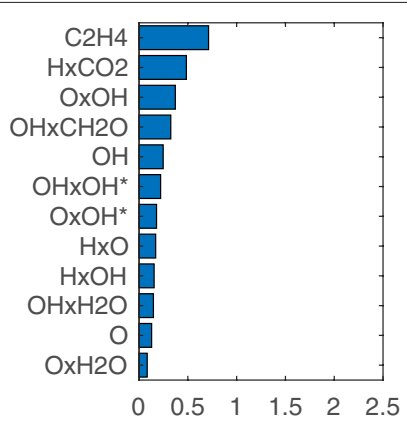

A $Z+$ at $x=30 \mathrm{~mm}$

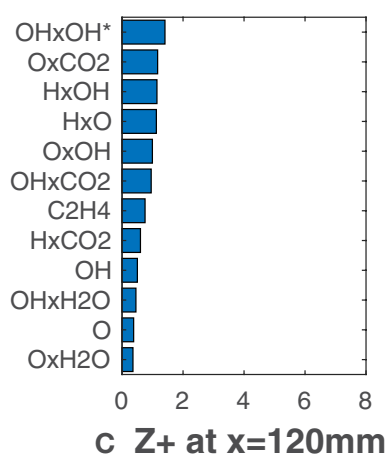

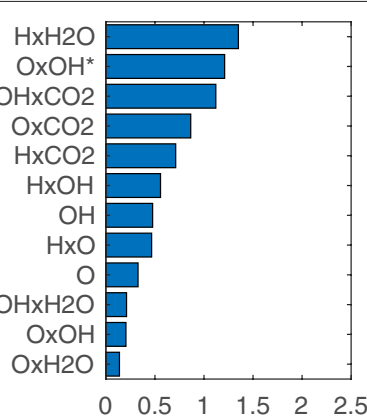

B $\mathrm{Z}+$ at $\mathrm{x}=60 \mathrm{~mm}$

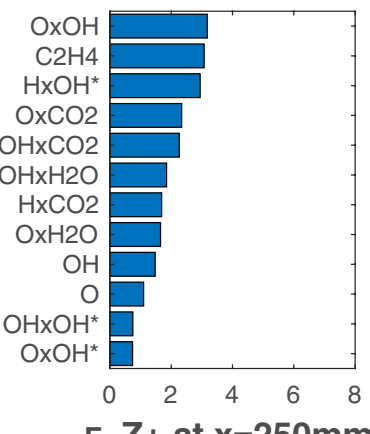

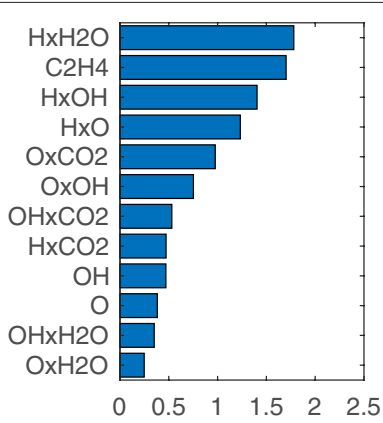

C $Z+$ at $x=90 \mathrm{~mm}$

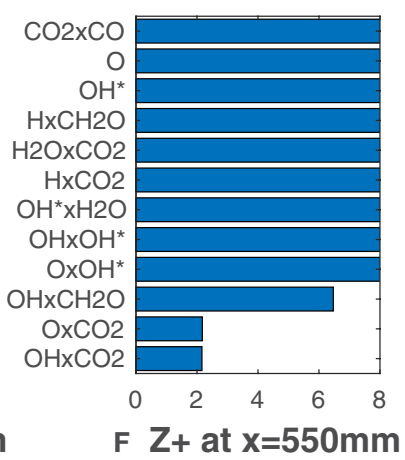

FIGURE 8 | HM3 case: best correlated markers at various axial locations. Lower $Z_{S}^{+}(v)$ values mean better correlation. Here $v$ comprehends both $X_{\alpha}$ and their combinations. 

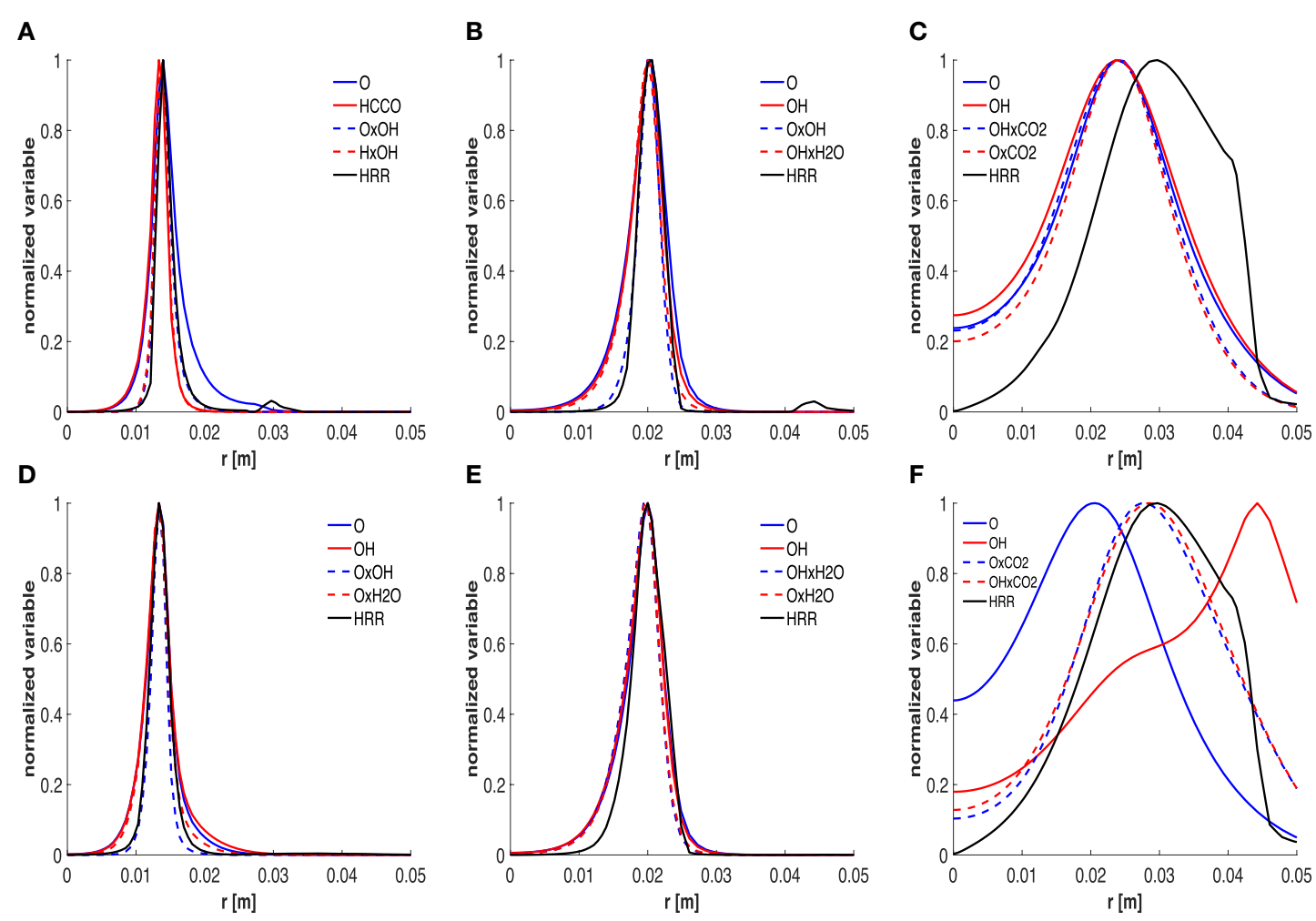

FIGURE 9 | Trends of normalized HRR, top-two mole fractions and combinations at 60 (A,D), 120 (B,E) and 550 (C,F) mm, respectively. First and second row refer to the HM1 and HM3 cases, respectively.

at $x=150 \mathrm{~mm}$ and $x=450 \mathrm{~mm}$. For each part, the best HRR marker combination is reported.

\section{CONCLUSION}

The choice of the right HRR marker is fuel-mixture specific and depends also on operative conditions. Therefore, the applicability of conventional HRR markers is not universal and should be tested for different flame configurations. To further investigate the applicability of the different available markers, numerical simulations of the Adelaide JHC were carried out with detailed chemistry, including the excited species $\mathrm{OH}^{*}$. The interesting feature of the JHC is the possibility to module oxygen dilution and the change in combustion behavior observed when the entrained oxygen from surroundings changes the flame from invisible to visible. Hence, correlations between HRR and both species mole fractions and reaction rates were investigated at various axial locations along the radial direction for two level of coflow oxygen mass fractions, $3 \%$ and $9 \%$.

In summary, in a clear distinction among $Z_{s}^{+}\left(X_{\alpha}\right)$ values cannot be made for the HM1 case in the first $120 \mathrm{~mm}$ of flame. In this range the radical $\mathrm{OH}$ is always one of the four top markers (Figure 3). Further downstream from the burner, the top-three markers are $\mathrm{O}, \mathrm{OH}, \mathrm{OH}^{*}$ radicals. The reaction rates that better correlate with the HRR are shown to belong mostly to reactions of the $\mathrm{OH}^{*}$ sub-mechanism and involve primarily these radicals together with other species such as $\mathrm{H}$, $\mathrm{O}_{2}, \mathrm{HO}_{2}, \mathrm{H}_{2} \mathrm{O}_{2}, \mathrm{H}_{2} \mathrm{O}, \mathrm{CO}, \mathrm{CO}_{2}$. Some of these appearing only at high axial locations. For the HM3 configuration, a very good agreement between the top-three radicals $\mathrm{O}, \mathrm{OH}, \mathrm{OH}^{*}$ and the HRR was found right from the first axial location (Figure 5), suggesting that a higher oxygen level allows better correlation with the HRR. This is in line with the change in the results of the HM1 case, since beyond $x=100 \mathrm{~mm}$, the entrained air increase the available oxygen for the flame (Dally et al., 2002; Medwell et al., 2007). With regard to the most correlated reaction rates, their relative reactions involve again the aforementioned 10 species.

Even though conventional HRR markers such as $\mathrm{OH}$ and $\mathrm{OH}^{*}$ perform well along most of the flame, a better detection of the reaction zone may be achieved using appropriate combinations of species. Considering the change of the combustion behavior due to the entrained oxygen from the air stream, different parts of the flame should be detected by different markers. For the HM1 case, the combination of $\mathrm{O}$ and $\mathrm{OH}$ mole fractions seems to be the right choice for the MILD region while beyond $x=150 \mathrm{~mm}$, the HRR is well captured by the product $\mathrm{OxCO}_{2}$, for both the configurations. Finally, only in the region far from the nozzle, i.e., 
A

[W]

2

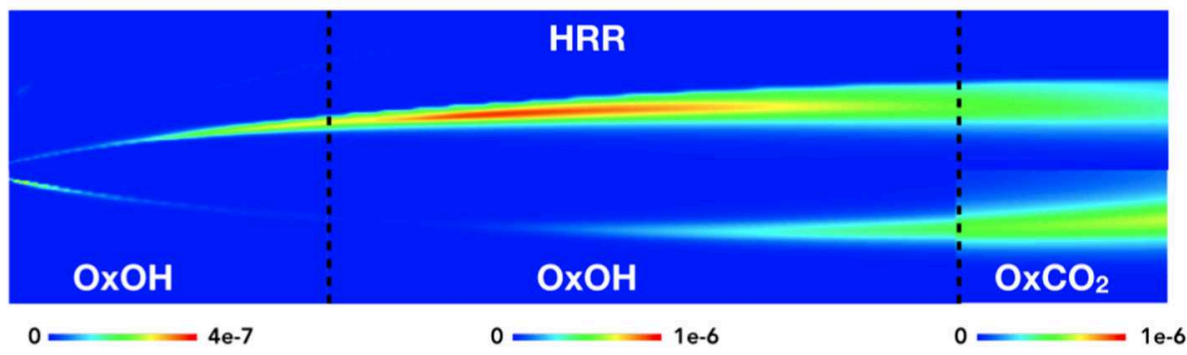

HM1

B
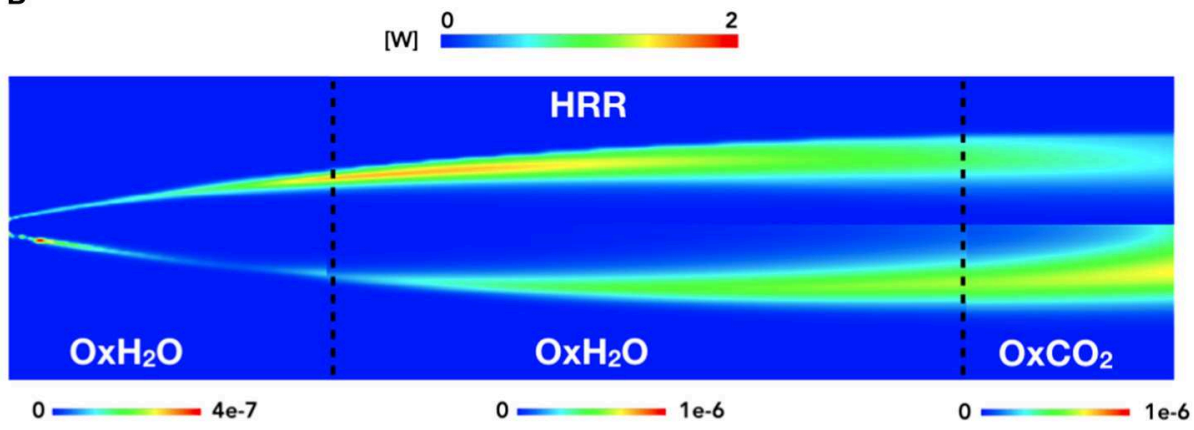

HM3

FIGURE 10 | HM1 and HM3 contour plots of HRR compared to species products contours. The three zones are split as follows: from 0 to $150 \mathrm{~mm}$, from 150 to 450 $\mathrm{mm}$, and from 450 to $550 \mathrm{~mm}$.

the last $150 \mathrm{~mm}$ of the studied domain, the low and wide values of HRR are better captured by combinations of $\mathrm{O}$ and $\mathrm{OH}$ with carbon dioxide.

The applicability of these markers for other conditions and fuel mixtures will be subject of future studies.

\section{DATA AVAILABILITY STATEMENT}

All datasets generated for this study are included in the article.

\section{AUTHOR CONTRIBUTIONS}

MF carried out the numerical simulations and the postprocessing, and lead the manuscript writing. RA and DB contributed to the CFD simulations and paper writing. CG and

\section{REFERENCES}

Aminian, J., Galletti, C., Shahhosseini, S., and Tognotti, L. (2012). Numerical investigation of a mild combustion burner: analysis of mixing field, chemical kinetics and turbulence-chemistry interaction. Flow Turbul. Combust. 88, 597-623. doi: 10.1007/s10494-0129386-z

Bowman, C. T., Hanson, R. K., Davidson, D. F., Gardiner, W. C. Jr., Lissianski, V., Smith, G. P., et al. (2020). Gri 2.11 Mechanism. Available online at: http://www. me.berkeley.edu/gri_mech/

Chomiak, J. (1990). Combustion: A Study in Theory, Fact and Application. New York, NY: Abacus Press; Gorden and Breach Science Publishers.
AP supervised the work, critically discussed the results, and contributed to the writing.

\section{FUNDING}

This project has received funding from the European Research Council (ERC) under the European Union's Horizon 2020 research and innovation programme under grant agreement no. 714605. MF wishes to thank the Fonds de la Recherche Scientifique FNRS Belgium for financing his research.

\section{ACKNOWLEDGMENTS}

The authors thank B. B. Dally at University of Adelaide for granting access to the experimental data.

Christo, F., and Dally, B. (2005). Modeling turbulent reacting jets issuing into a hot and diluted coflow. Combust. Flame 142, 117-129. doi: 10.1016/j.combustflame.2005.03.002

Dally, B., Karpetis, A., and Barlow, R. (2002). Structure of turbulent nonpremixed jet flames in a diluted hot coflow. Proc. Combust. Inst. 29, 1147-1154. doi: 10.1016/S1540-7489(02)80145-6

Doan, N., Swaminathan, N., and Minamoto, Y. (2018). Dns of mild combustion with mixture fraction variations. Combust. Flame 189, 173-189. doi: 10.1016/j.combustflame.2017.10.030

Fayoux, A., Zähringer, K., Gicquel, O., and Rolon, J. (2005). Experimental and numerical determination of heat release in counterflow premixed laminar flames. Proc. Combust. Inst. 30, 251-257. doi: 10.1016/j.proci.2004.08.210 
Ferrarotti, M., Li, Z., and Parente, A. (2019). On the role of mixing models in the simulation of mild combustion using finite-rate chemistry combustion models. Proc. Combust. Inst. 37, 4531-4538. doi: 10.1016/j.proci.2018.07.043

Golovitchev, V., and Chomiak, J. (2001). "Numerical modeling of high temperature air flameless combustion," in Proceedings of the 4th International Symposium on High Temperature Air Combustion and Gasification (HiTACG) (Rome), 27-30.

Kathrotia, T., Fikri, M., Bozkurt, M., Hartmann, M., Riedel, U., and Schulz, C. (2010). Study of the $\mathrm{h}+\mathrm{O}+\mathrm{m}$ reaction forming $\mathrm{OH}^{*}$ : Kinetics of $\mathrm{OH}^{*}$ chemiluminescence in hydrogen combustion systems. Combust. Flame 157, 1261-1273. doi: 10.1016/j.combustflame.2010.04.003

Kathrotia, T., Riedel, U., Seipel, A., Moshammer, K., and Brockhinke, A. (2012). Experimental and numerical study of chemiluminescent species in lowpressure flames. Appl. Phys. B 107, 571-584. doi: 10.1007/s00340-012-5002-0

Li, Z., Ferrarotti, M., Cuoci, A., and Parente, A. (2018). Finite-rate chemistry modelling of non-conventional combustion regimes using a partially-stirred reactor closure: combustion model formulation and implementation details. Appl. Energy 225, 637-655. doi: 10.1016/j.apenergy.2018.04.085

Medwell, P. R., Kalt, P., and Dally, B. (2007). Simultaneous imaging of oh, formaldehyde, and temperature of turbulent nonpremixed jet flames in a heated and diluted coflow. Combust. Flame 148, 48-61. doi: 10.1016/j.combustflame.2006.10.002

Minamoto, Y., and Swaminathan, N. (2014). Scalar gradient behaviour in mild combustion. Combust. Flame 161, 1063-1075. doi: 10.1016/j.combustflame.2013.10.005

Mulla, I., Dowlut, A., Hussain, T., Nikolaou, Z., Chakravarthy, S., Swaminathan, N., et al. (2016). Heat release rate estimation in laminar premixed flames using laser-induced fluorescence of ch2o and h-atom. Combust. Flame 165, 373-383. doi: 10.1016/j.combustflame.2015.12.023

Najm, H., Knio, O., Paul, P., and Wyckoff, P. (1998a). A study of flame observables in premixed methane - air flames. Combust. Sci. Technol. 140, 369-403. doi: 10.1080/00102209808915779

Najm, H., Paul, P., Mueller, C., and Wyckoff, P. (1998b). On the adequacy of certain experimental observables as measurements of flame burning rate. Combust. Flame 113, 312-332. doi: 10.1016/S0010-2180(97)00 209-5

Nikolaou, Z., and Swaminathan, N. (2014). Heat release rate markers for premixed combustion. Combust. Flame 161, 3073-3084. doi: 10.1016/j.combustflame.2014.05.019

Parente, A., Malik, M., Contino, F., Cuoci, A., and Dally, B. (2016). Extension of the eddy dissipation concept for turbulence/chemistry interactions to mild combustion. Fuel 163, 98-111. doi: 10.1016/j.fuel.2015. 09.020

Paul, P., and Najm, H. (1998). Planar laser-induced fluorescence imaging of flame heat release rate. Symp. (Int.) Combust. 27, 43-50. doi: 10.1016/S0082-0784(98)80388-3

Pope, S. (1978). An explanation of the turbulent round-jet/plane-jet anomaly. AIAA J. 16, 279-281. doi: 10.2514/3.7521
Pope, S. (1997). Computationally efficient implementation of combustion chemistry using in situ adaptive tabulation. Combust. Theory Model. 1, 41-63. doi: 10.1080/713665229

Raman, V., and Pitsch, H. (2007). A consistent LES/filtered-density function formulation for the simulation of turbulent flames with detailed chemistry. Proc. Combust. Inst. 31, 1711-1719. doi: 10.1016/j.proci.2006.07.152

Richter, M., Collinm, R., Nygren, J., Aldeacute, M., Hildingsson, N., and Johansson, B. (2005). Studies of the combustion process with simultaneous formaldehyde and $\mathrm{OH}$ PLIF in a direct-injected hcci engine. JSME Int. J. Ser. B Fluids Ther. Eng. 48, 701-707. doi: 10.1299/jsmeb.48.701

Röder, M., Dreier, T., and Schulz, C. (2013). Simultaneous measurement of localized heat-release with $\mathrm{OH} / \mathrm{CH} 2 \mathrm{O}-\mathrm{LIF}$ imaging and spatially integrated $\mathrm{OH}^{*}$ chemiluminescence in turbulent swirl flames. Proc. Combust. Inst. 34 3549-3556. doi: 10.1016/j.proci.2012.06.102

Sanders, J., and Gökalp, I. (1998). Scalar dissipation rate modelling in variable density turbulent axisymmetric jets and diffusion flames. Phys. Fluids 10, 938-948. doi: 10.1063/1.869616

Sidey, J., and Mastorakos, E. (2015). Visualization of mild combustion from jets in cross-flow. Proc. Combust. Inst. 35, 3537-3545. doi: 10.1016/j.proci.2014.07.028

Smith, G., Luque, J., Park, C., Jeffries, J., and Crosley, D. (2002). Low pressure flame determinations of rate constants for $\mathrm{OH}(\mathrm{A})$ and $\mathrm{CH}(\mathrm{A})$ chemiluminescence. Combust. Flame 131, 59-69. doi: 10.1016/S0010-2180(02)00399-1

Tamura, M., Berg, P., Harrington, J., Luque, J., Jeffries, J., Smith, G., et al. (1998). Collisional quenching of $\mathrm{CH}(\mathrm{A}), \mathrm{OH}(\mathrm{A})$, and $\mathrm{NO}(\mathrm{A})$ in low pressure hydrocarbon flames. Combust. Flame 114, 502-514. doi: 10.1016/S0010-2180(97)00324-6

Vagelopoulos, C., and Frank, J. (2005). An experimental and numerical study on the adequacy of $\mathrm{CH}$ as a flame marker in premixed methane flames. Proc. Combust. Inst. 30, 241-249. doi: 10.1016/j.proci.2004.08.243

Wang, F., Mi, J., Li, P., and Zheng, C. (2011). Diffusion flame of a $\mathrm{CH} 4 / \mathrm{H} 2$ jet in hot low-oxygen coflow. Int. J. Hyd. Energy 36, 9267-9277. doi: 10.1016/j.ijhydene.2011.04.180

Ye, I. (2011). Investigation of the scalar variance and scalar dissipation rate in URANS and LES (Ph.D. thesis), University of Waterloo, Waterloo, ON, Canada.

Conflict of Interest: The authors declare that the research was conducted in the absence of any commercial or financial relationships that could be construed as a potential conflict of interest.

Copyright (c) 2020 Ferrarotti, Amaduzzi, Bascherini, Galletti and Parente. This is an open-access article distributed under the terms of the Creative Commons Attribution License (CC BY). The use, distribution or reproduction in other forums is permitted, provided the original author(s) and the copyright owner(s) are credited and that the original publication in this journal is cited, in accordance with accepted academic practice. No use, distribution or reproduction is permitted which does not comply with these terms. 